\title{
A Numerical Study on Generation Mechanism of Vertical Cracks in Top Coat of TBCs During APS Deposition
}

\author{
K. Ito, H. Kuriki, and M. Enoki
}

(Submitted November 9, 2014; in revised form January 14, 2015)

\begin{abstract}
Clarification of crack generation mechanism in the top coat of the thermal barrier coatings (TBCs) during atmospheric plasma spray process is important to improve the reliability of TBC. In this study, finite element analyses of stress and strain during the deposition process were conducted with layer-bylayer method to understand the cracking behaviors. Stress relaxation by generation of vertical cracks was expressed as an elasto-plastic behavior of the coating. The effects of pre-heating temperature of the substrate and plasma power on crack development were analyzed by changing of the initial and atmospheric temperatures in simulation, respectively. The simulation results of radial strain explained the experimental results of crack monitoring by non-contact laser acoustic emission method.
\end{abstract}

Keywords accoustic emission, finite element modeling, fracture, heat transfer, in situ monitoring, segmented coatings, thermal stress

\section{Introduction}

Thermal barrier coatings (TBCs) are used to protect metallic parts which are exposed to high temperature for example in gas turbines and aero-engines. Atmospheric plasma spray (APS) and electron-beam physical vapor deposition (EB-PVD) are widely used methods for deposition of the top coat of TBCs. Among them, APS is mainly used because it provides many advantages such as low cost, high deposition rate, and applicability over large area. However, vertical and horizontal cracks are often found in the top coat of TBC by APS process, which are parallel and perpendicular to the deposition direction, respectively. The vertical cracks tend to improve the life time of TBC because they reduce the thermal stress in the top coat during in-service period. On the contrary, horizontal cracks degrade the life time of TBC because they induce delamination of the top coat (Ref 1$)$. Therefore, clarification of the mechanism of crack generation is needed to improve the lifetime of top coats deposited by APS. For this objective, laser acoustic emission (AE) method has been applied in our research group as a monitoring method of the crack generation (Ref 2-6), and a relationship between the temperature difference in the

K. Ito, H. Kuriki, and M. Enoki, The University of Tokyo, Tokyo, Japan. Contact e-mail: ito@rme.mm.t.u-tokyo.ac.jp. top coat and the crack generation has been gradually clarified experimentally (Ref 7).

Various finite element analysis (FEA) methods have been applied for simulation of TBC by APS. Sfar et al. (Ref 8) and Ranjbar-Far et al. (Ref 9) inspected the effect of roughness of the thermally grown oxide (TGO) and the bond coat surfaces on the stress distribution and crack propagation around these surfaces. Gilvert et al. (Ref 10,11) and Taniguchi et al. (Ref 3) inspected the crack generation during cooling period after spraying. Layer-by-layer method is widely used to simulate deposition processes by thermal spraying (Ref 12, 13). In conventional layer-by-layer method, thermal spray process is treated as a sequential deposition of layers of the top coat with a certain thickness. However, Chen et al. (Ref 14) simulated the temperature field during the deposition process in consideration of the motion of the spray torch which uses stochastic deposition numerical model based on Gaussian distribution. Large quenching stress in a splat was generated after its impact on the substrate and solidification; however, the stress was relaxed by generation of microcracks in the splat (Ref 15, 16). Therefore, perfect elasto-plasticity was introduced in simulation of thermal spray processes for consideration of the stress relaxation to avoid unnatural large stress (Ref 13).

Our previous experiments (Ref 6,7) showed that only vertical cracks were observed in the YSZ top coat during APS process with a special "loop" driving pattern of the torch. AE monitoring showed that these vertical cracks were due to thermal tensile stress because of the rapid heat input on the surface induced by the temperature difference in the top coat. In this study, an FEA of APS deposition process of the top coat of TBC was conducted by the layer-by-layer model. The simulation results were compared with the experimental results of AE monitoring and cross section observation of the top coat. 


\section{Simulation Method}

\subsection{Layer-by-Layer Model of Deposition}

Temperature, stress, and strain during deposition process by APS were simulated with Abaqus 6.11 (DassaultSystèmes S.A.) finite element code. Layer-by-layer model i.e., sequential deposition of layers with a certain thickness was used to simplify the deposition process. Sprayed molten particles solidify immediately after their impact on the substrate in APS; however, solidification needs much longer time than deformation (Ref 17). Therefore, instantaneous overlapping of a new hot layer on the substrate or the existing layers in the layer-by-layer model is reasonable. A frame format of the layer-by-layer model is shown in Fig. 1. A term "step" in this figure was defined to express the time for deposition of one layer; then "step 1" means the time between the deposition of the first and second layers. Time length of each step was decided by the experimental results. Heat flux and high initial temperature of newly deposited layer was used for heat supply to the surface of the top coat. Also, the steps were separated into "spraying steps" and "cooling steps." During the spraying steps, the top surface of the specimen was heated by spraying with heat-transfer coefficient $h_{\mathrm{s}}$ and atmospheric temperature $T_{\mathrm{s}}$. And the other surfaces were air-cooled with heat-transfer coefficient $h_{\mathrm{c}}$ and atmospheric temperature $T_{\mathrm{c}}$ in the same time. On the other hand, whole surfaces of the specimen were aircooled with $h_{\mathrm{c}}$ and $T_{\mathrm{c}}$ during the cooling time. In this study, temperature field in the specimen during APS deposition process was calculated by transient heattransfer analysis method for estimation of the stress and strain in the specimen.

\subsection{Geometry of the Specimen}

Axisymmetric ( $Z$ axis is the rotation axis) $2 \mathrm{D}$ mesh for FEA in this study is shown in Fig. 2. The interfaces between the substrate and the bond coat as well as between the bond coat and the top coat were assumed perfectly flat. The specimen size was the same as the experiment i.e., $30 \mathrm{~mm}$ in diameter, $5 \mathrm{~mm}$ in thickness of the substrate, $0.12 \mathrm{~mm}$ in thickness of the bond coat. Two driving patterns of the plasma torch in the experiment which were called as "loop" and "zigzag" were also used for simulation in this study. The diameter of spraying area was about $20 \mathrm{~mm}$ and the scanning pitch was $5 \mathrm{~mm}$ in the "zigzag" experiments. Then, a specific point on the specimen would be sprayed three or four times during in one pass. Therefore, three spraying steps were defined in one pass in the simulation of the zigzag pattern i.e., one pass was separated to three thin layers of the top coat for deposition. Total $500 \mu \mathrm{m}(100 \mu \mathrm{m} /$ pass $\times 5$ passes $)$ of deposition of the top coat was simulated in consideration of the experimental conditions of pass numbers and thickness per one pass. Meanwhile, also three spraying steps were defined in one pass in the loop pattern and total $700 \mu \mathrm{m}(35 \mu \mathrm{m} /$ pass $\times 20$ passes $)$ of deposition of the top coat was simulated. Then, the thickness of one step of the
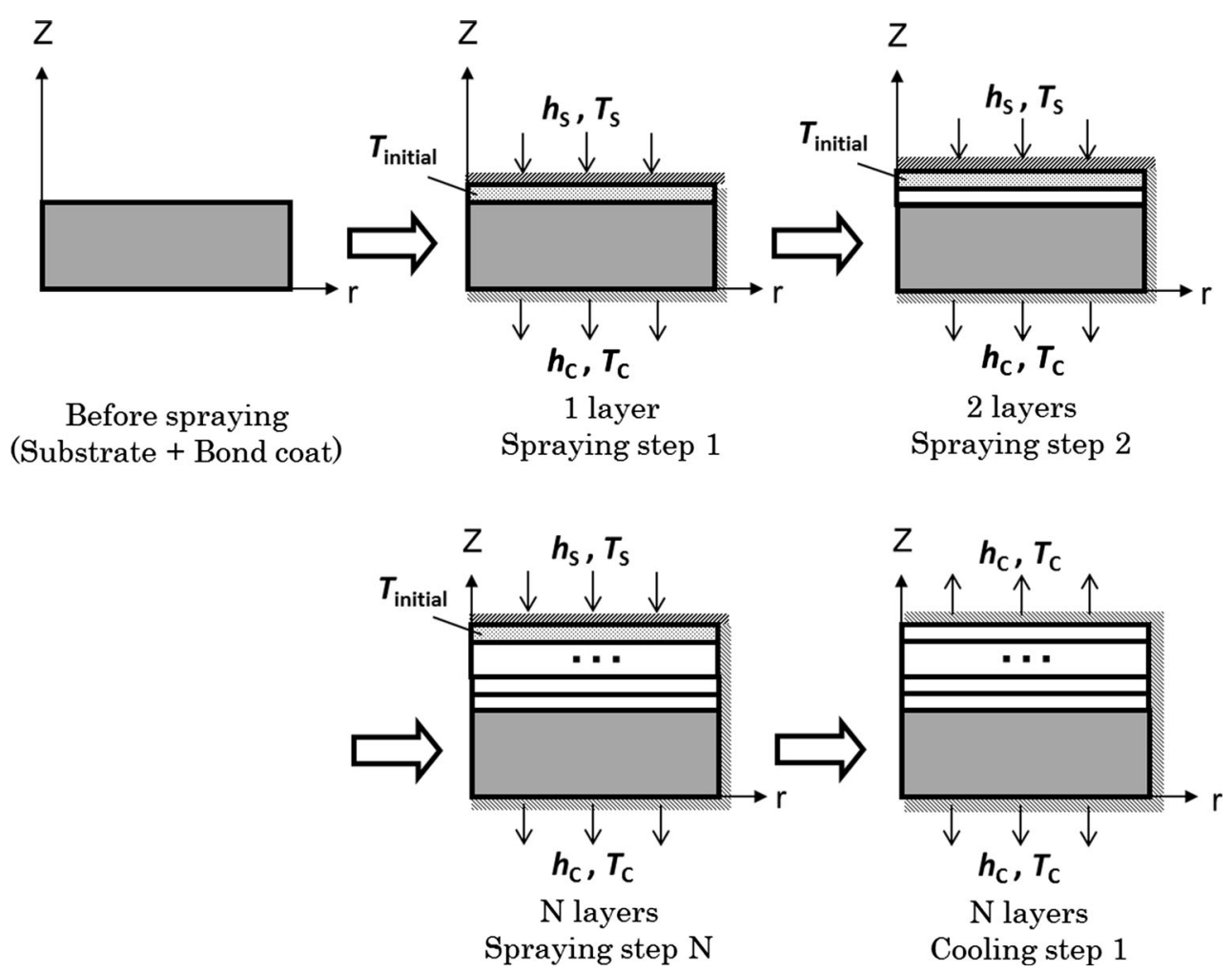

Fig. 1 Frame format of layer-by-layer model 

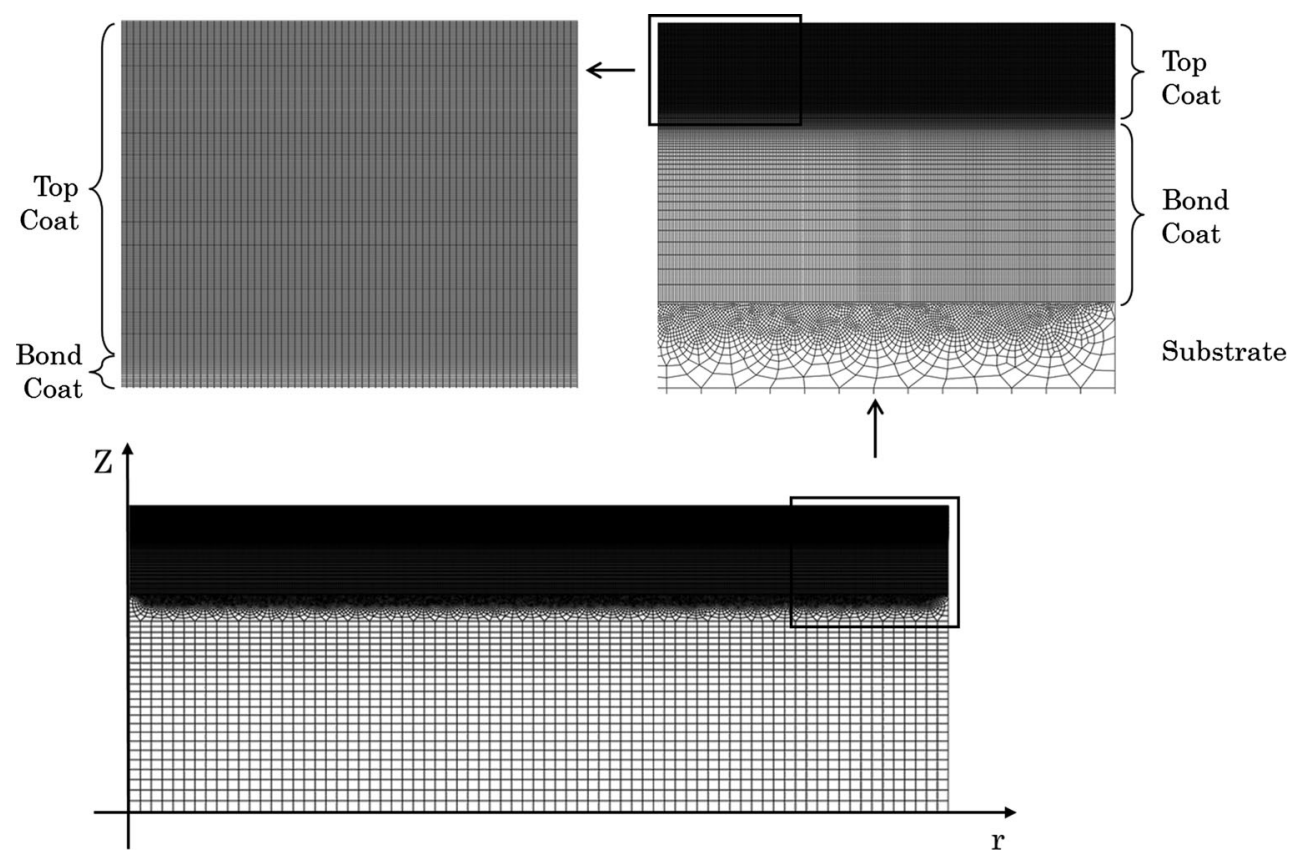

Fig. 2 Axisymmetric 2D mesh of TBC for FEA

Table 1 Temperature-dependent properties of materials

\begin{tabular}{|c|c|c|c|c|c|c|c|}
\hline Material & $\boldsymbol{T},{ }^{\circ} \mathbf{C}$ & $\begin{array}{c}\text { Thermal } \\
\text { conductivity, } \\
\text { W/mK }\end{array}$ & $\begin{array}{c}\text { Specific } \\
\text { heat, J/kg K }\end{array}$ & $\begin{array}{c}\text { Density, } \\
\mathbf{k g} / \mathrm{m}^{3}\end{array}$ & $\begin{array}{l}\text { Young's } \\
\text { modulus, } \\
\text { GPa }\end{array}$ & $\begin{array}{l}\text { Poisson's } \\
\text { ratio }\end{array}$ & $\begin{array}{l}\text { Thermal } \\
\text { expansion } \\
\text { coefficient, } \\
\times 10-6 / K\end{array}$ \\
\hline \multirow[t]{4}{*}{ Inconel 601} & 20 & 11.2 & 448 & 8110 & 206.5 & 0.272 & $\ldots$ \\
\hline & 100 & $\ldots$ & $\ldots$ & 8110 & $\ldots$ & $\ldots$ & 13.75 \\
\hline & 300 & 16.0 & 523 & 8110 & 191.2 & 0.296 & 14.58 \\
\hline & 700 & 22.8 & 632 & 8110 & 161.3 & 0.340 & 16.11 \\
\hline \multirow[t]{3}{*}{ CoNiCrAlY } & 25 & 3.82 & 460 & 6290 & 64.5 & 0.30 & 10.3 \\
\hline & 725 & 7.93 & 617 & 6290 & 53.0 & 0.30 & 11.0 \\
\hline & 1300 & 9.86 & 620 & 6290 & 43.0 & 0.30 & 11.4 \\
\hline \multirow[t]{3}{*}{ YSZ } & 25 & 0.67 & 420 & 5600 & 13.6 & 0.25 & 7.5 \\
\hline & 725 & 0.58 & 547 & 5600 & 10.4 & 0.25 & 9.0 \\
\hline & 1300 & 0.56 & 569 & 5600 & 8.0 & 0.25 & 9.7 \\
\hline
\end{tabular}

top coat in simulation became about 33 and $12 \mu \mathrm{m}$ in the zigzag and loop patters, respectively. All these parameters of the specimen and spraying were referred to our previous experiments (Ref 6,7). The minimum size of the mesh was $2 \mu \mathrm{m}$ and the total number of nodes was about 490,000. This mesh size was sufficiently small because smaller sizes were preliminarily checked not to make 5\% or more difference in the results of stress and strain. The element type in the transient heat-transfer analysis and stress analysis was DCAX8 (eight-node quadrangle heattransfer element) and CAX8R (eight-node quadrangle axisymmetric stress element), respectively.

\subsection{Material Characteristics}

Temperature-dependent properties of materials are shown in Table 1 (Ref 18, 19). Also plastic deformation properties of materials are shown in Table 2
(Ref $13,15,16,18)$ where $T$ was the temperature, $\sigma_{y}$ was the yield stress of the top coat, and $H$ was the plasticity coefficient. Bilinear approximation was used in plastic region. Stress in the ceramic top coat was relaxed by macro- and microcracks which were developed in the whole of the top coat although they were brittle materials. These microcracks were generated in splat by large tensile thermal stress after its impact and solidification. YSZ was considered as a perfect elasto-plastic material in this study to simulate this stress relaxation due to generation of the macrocracks. Therefore, $\sigma_{y}$ in Table 2 is defined as the stress level when the beginning of generation of the macrocracks. In this study, an elastic analysis without consideration of plastic deformation of YSZ and an elastoplastic analysis with consideration of plastic deformation with values in Table 2 were conducted to confirm the applicability of this plastic deformation behavior to crack generation in the top coat. 


\subsection{Thermal Boundary Conditions}

Initial temperature of newly depositing layer of the top coat in the layer-by-layer model was set to $2205^{\circ} \mathrm{C}$ (Ref 12). Stress in the top coat was assumed free at this temperature. Conditions in the transient thermal conduct analysis (Ref 13) are shown in Table 3. Each value was decided to minimize the error of the temperature at the center of the substrate between the experimental and simulated results. At first, $h_{\mathrm{s}}=h_{\mathrm{c}}$ and $T_{\mathrm{c}}=25^{\circ} \mathrm{C}$ were assumed to reduce the number of parameters. Only one heat-transfer coefficient $h$ was used although $h_{\mathrm{s}} \neq h_{\mathrm{c}}$ was estimated. Furthermore, the heat flux on the surface of the specimen could be controlled by $T_{\mathrm{s}}$ only, although it depended on $h$ and $T_{\mathrm{s}}$. It should be noted that $h$ and $T_{\mathrm{s}}$ in this analysis may be different from the actual values. Figure 3 shows the temperature error between the experiments and analysis at the center of the substrate. One of five $h$ from 160 to $200 \mathrm{~W} / \mathrm{m}^{2} \mathrm{~K}$ and one of five $T_{\mathrm{s}}$ from 2400 to $2800{ }^{\circ} \mathrm{C}$ were selected, and total 25 combinations were compared to the experimental result. As a consequence, the error became minimum when $h=190 \mathrm{~W} / \mathrm{m}^{2} \mathrm{~K}$ and $T_{\mathrm{s}}=2600{ }^{\circ} \mathrm{C}$ in case of the zigzag pattern.

In case of the zigzag pattern, the initial substrate temperature was modified because the pre-heating temperature was varied in the experiments. Meanwhile in case of the loop pattern, $T_{\mathrm{s}}$ was modified because the average temperature fluctuation on the surface of top coat in one pass $\left(T_{\mathrm{f}}\right)$ was varied in these experiments by changing of the plasma power (Ref 7). Temperature increase in the spraying steps became large by enlarging of $T_{\mathrm{s}}$ and it enabled expression of temperature fluctuation behaviors of experiments with different $T_{\mathrm{f}}$.

\section{Results and Discussion}

\subsection{Transient Heat-Transfer Analysis}

Experimental and simulated temperatures at the surface of the top coat and the center of the substrate are shown in Fig. 4. In this figure, the experiment was

Table 2 Plastic deformation properties of materials

\begin{tabular}{lccc}
\hline Material & $\boldsymbol{T},{ }^{\circ} \mathbf{C}$ & $\begin{array}{c}\text { Yield stress } \\
\text { of the top } \\
\text { coat } \boldsymbol{\sigma}_{\boldsymbol{y}}, \mathbf{M P a}\end{array}$ & $\begin{array}{c}\text { Plasticity } \\
\text { coefficient, } \\
\boldsymbol{H}, \mathbf{G P a}\end{array}$ \\
\hline Inconel 601 & 20 & 290 & 5 \\
& 200 & 236 & 5 \\
CoNiCrAlY & 500 & 203 & 5 \\
YSZ & All & 270 & 5 \\
\hline
\end{tabular}

conducted with the loop pattern, $50 \mathrm{~mm} / \mathrm{s}$ in torch velocity, $6 \mathrm{~s}$ in loop interval, $28 \mathrm{~kW}$ in the plasma power and without pre-heating. The simulation was conducted with $T_{\mathrm{s}}=6000 \mathrm{~K}$ condition. The substrate temperature was precisely represented because the boundary conditions were adjusted to fit the simulated temperature to the experimental temperature at this point. On the contrary, the simulated surface temperature became higher than the experimental one, especially at the local maximum. One of the reasons of the high surface temperature in simulation might be the layer-by-layer deposition despite the continuous and gradual deposition in real experiments. The surface temperature was easy to elevate when some amount of high temperature material was deposited at once. Furthermore, the surface temperature might be higher than the measured value because the response of the thermocouple was slower than the actual temperature elevation (Ref 7).

\subsection{Elasto-Plastic Analysis}

The stress distributions were obtained from elastic and elasto-plastic analyses until the substrate temperature was cooled down to $100{ }^{\circ} \mathrm{C}$ after the finish of deposition (see Fig. 5). Stress in radial direction on the interface between the top and bond coats is shown in this figure. The elastic analysis showed significantly larger stress distribution than the elasto-plastic analysis. Of course, such large stress could not be generated in the real coating because of the strength of the sprayed top coat. Furthermore, it was reported that the residual stress in the top coat after spraying was several tens of $\mathrm{MPa}$ by $\mathrm{x}$-ray diffraction method (Ref 13, 20, 21). Then, a consideration of stress relaxation due to crack generation was necessary for analysis of the deposition process of ceramic coatings. Therefore, elasto-plastic analysis in this study is one of the effective methods.

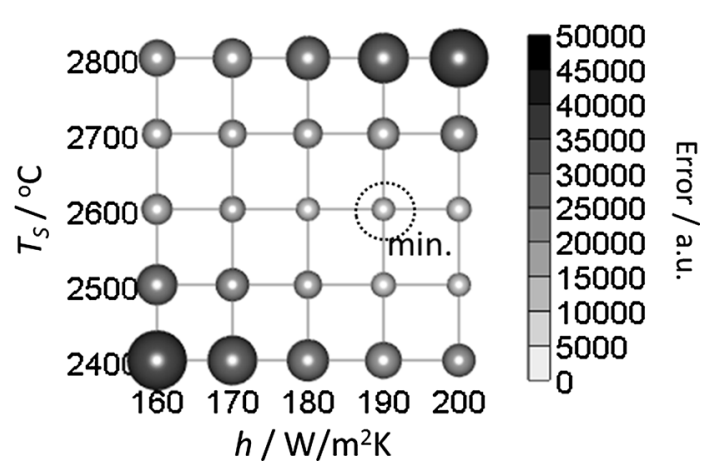

Fig. 3 Temperature error between the experiment and analysis at the center of the substrate

Table 3 Boundary conditions for transient thermal conduct analysis

\begin{tabular}{lccccc}
\hline Scanning Pattern & $\boldsymbol{h}_{\mathbf{S}}, \mathbf{W} / \mathbf{m}^{\mathbf{2}} \mathbf{K}$ & $\boldsymbol{T}_{\mathbf{S}},{ }^{\circ} \mathbf{C}$ & $\boldsymbol{h}_{\mathbf{C}}, \mathbf{W}^{\prime \mathbf{m}^{\mathbf{2}} \mathbf{K}}$ & $\boldsymbol{T}_{\mathbf{C}},{ }^{\circ} \mathbf{C}$ & Initial temperature, ${ }^{\circ} \mathbf{C}$ \\
\hline Zigzag Pattern & 190 & 2600 & 190 & 25 & $25,150,300,470,700$ \\
Loop pattern & 190 & $3000,4500,6000$ & 190 & 25 & 25 \\
\hline
\end{tabular}



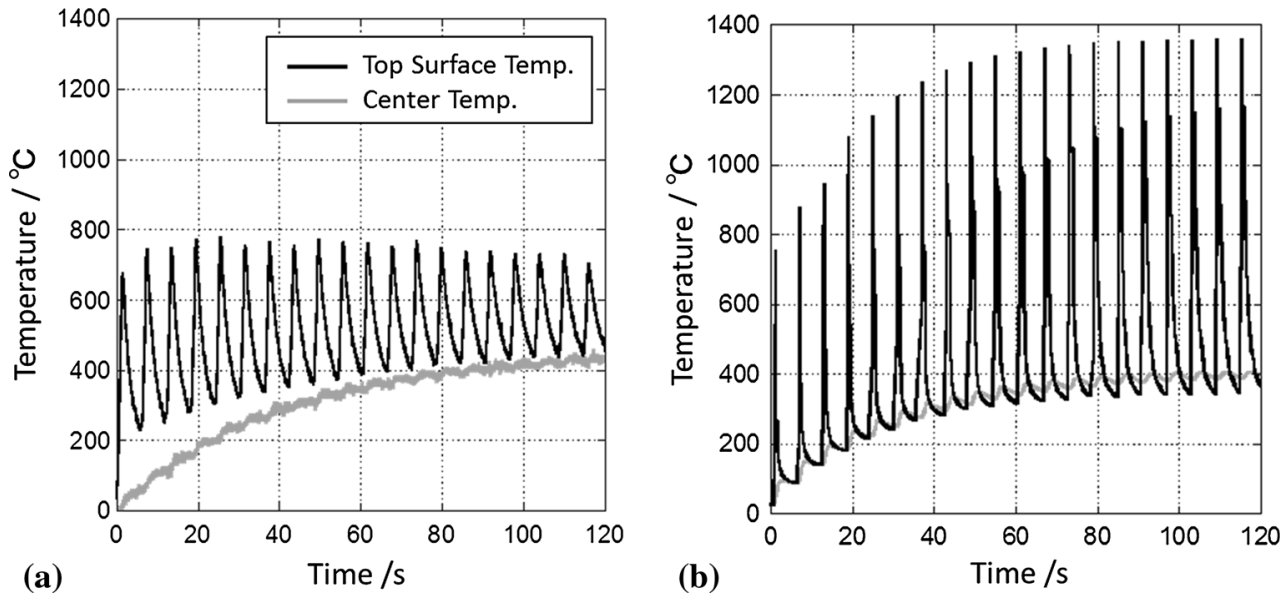

Fig. 4 Temperature history of (a) experimental and (b) simulated results
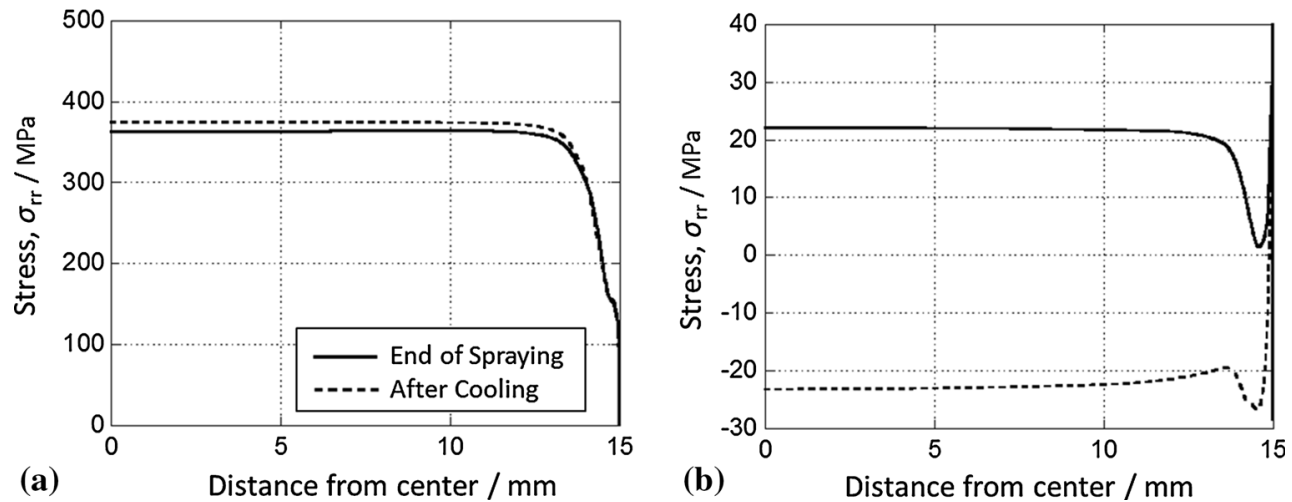

Fig. 5 Stress distributions from (a) elastic and (b) elasto-plastic analyses (Zigzag pattern, initial temperature of the specimen: $25^{\circ} \mathrm{C}$ )

Figure 6 shows the stress and the strain distributions in radial direction by elasto-plastic analysis on the interface between the top and bond coats when the deposition was just finished. The stress level in the elasto-plastic analysis was almost constant by changing the initial temperature of the substrate because the material reached to the plastic zone. On the contrary, the strain depended on the initial temperature of the substrate. The experimental and simulated results can be corresponded to the strain because the crack development degree depended on the pre-heating temperature in experimental results. The strain which corresponded to the vertical cracks was radial or circumferential direction because the most of the observed cracks especially from the experiments with the loop pattern were vertical ones. The analysis results were evaluated using the radial strain because the radial and circumferential strains became almost the same value.

\subsection{Strain History}

Figure 7 shows the temperature history of the specimen and the strain history on the interface between the top and bond coats. The strain (dotted line in the figure) showed a significant increase tendency during temperature increasing although the specimen temperature showed cyclic increasing and decreasing during spraying. Generally in plasma spraying process, thermal stress is considered to be generated by mismatch of thermal expansion coefficient between the top coat, bond coat and substrate or temperature gradient in the top coat. The thermal strain should be the same manner. Tensile strain occurs in the top coat, especially around the interface between the top and bond coats when the surface is heated by spraying because the thermal expansion coefficient of the bond coat and the substrate is larger than the top coat. Therefore, the strain is considered to be large when the initial temperature of the substrate is low because the effect of mismatching of the thermal expansion coefficient also becomes large.

\subsection{Vertical Cracking Behavior}

Figure 8 shows the schematic of generation of temperature gradient in the top coating during spraying. The temperature distribution before one-time of spraying was almost uniform. Then, a large temperature gradient would be generated in the top coat when the surface was heated by spraying (Ref 7). Figure 9(a) is an example of vertical crack, which suggests that the crack developed upward by the shape of branching. Figure 9(b) is a sample contour 

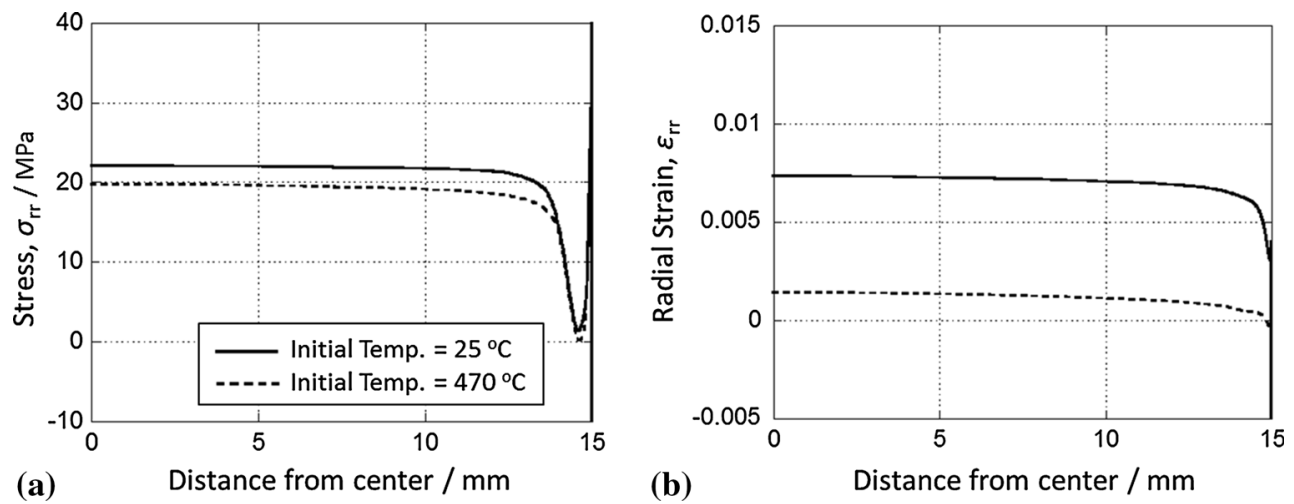

Fig. 6 (a) Stress and (b) strain distributions in radial direction by elasto-plastic analysis on the interface between the top and bond coats at the time of spray finish
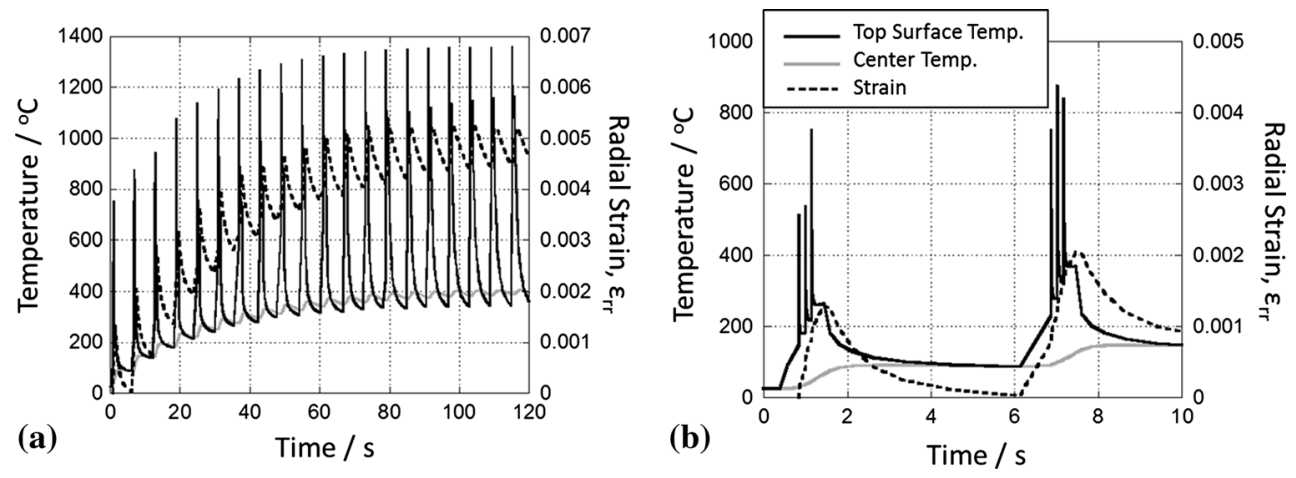

Fig. 7 Temperature and strain on the interface between the top and bond coats. (b) is a magnified image of (a)

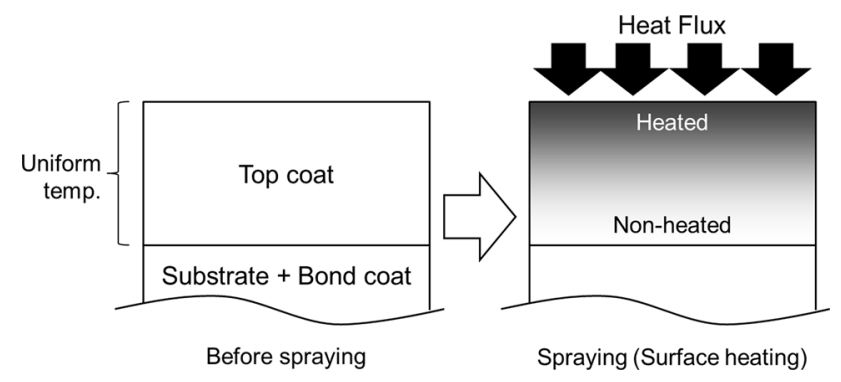

Fig. 8 Generation of temperature gradient in the top coat by spraying

plot of the strain in the top coat when the deposition was finished. The radial strain reached the peak on the interface between the top and bond coats and gradually diminished to the surface of the top coat. Furthermore, the radial strain on the top surface was negative. Distribution of the strain was estimated as Fig. 9(b) because the strain in the top coat became large nearby the bond coat due to the mismatch of the thermal expansion coefficient and the temperature gradient in the top coat. This tendency of the crack propagation to the surface was explained by this strain distribution because a crack would be considered to be generated at the maximum strain point.

\subsection{Effect of the Initial Temperature}

Figure 10 shows the effect of the initial temperature of the substrate on the maximum radial strain on the interface between the top and bond coats. The radial strain became larger and smaller when the specimen was heated and cooled, respectively. Our previous result of laser AE monitoring showed that the most of cracks were generated during rapid heating by spraying (Ref 7). Therefore, the simulation results were corresponded to the experimental results of crack generation due to heating.

Furthermore, the strain after the deposition process became larger when the initial temperature was low. It can be considered that the strain became larger because the effect of the mismatching of the thermal expansion coefficient also became larger when the initial temperature of the substrate was low. Figure 11 shows the relationship among the initial temperature of the specimen, the total AE energy in each experiment, and the simulated radial strain. The AE energy and the strain became larger when the pre-heating temperature was low. Therefore, a relationship between development of vertical cracks and the initial temperature was explained by the radial strain because cracks were more developed in the lower initial temperature experiments. 


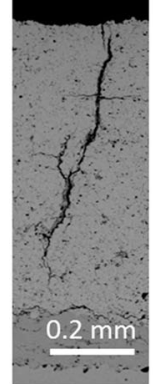

(a)

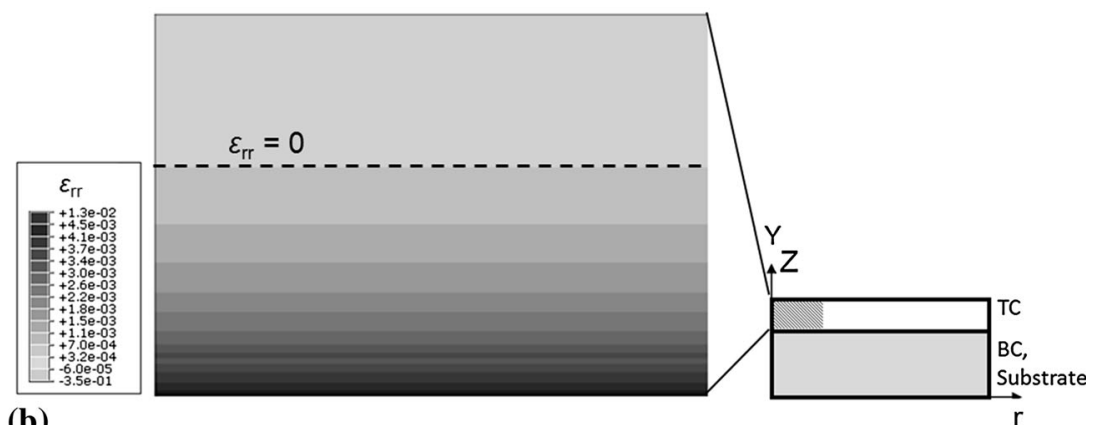

(b)

Fig. 9 (a) Observed vertical crack and (b) contour plot of the strain in the top coat when the deposition finish

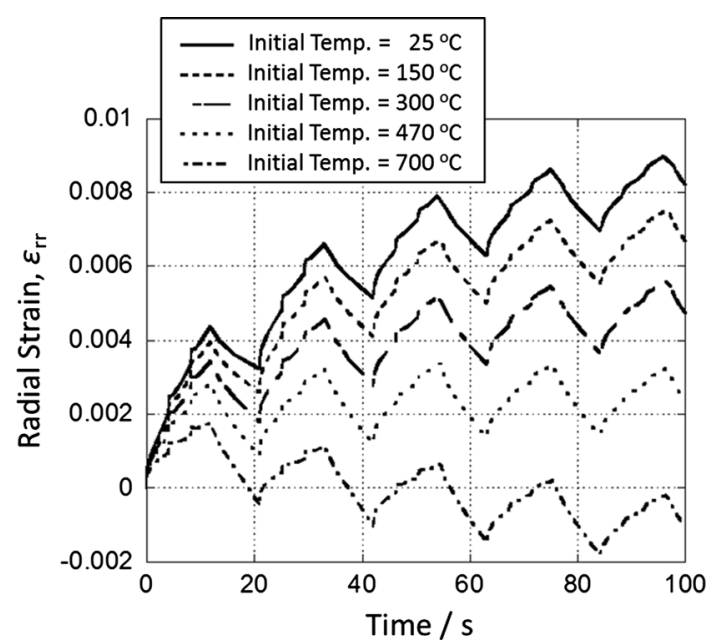

Fig. 10 Effect of the initial temperature of the substrate on the interface between the top and bond coats

\subsection{Effect of the Atmospheric Temperature}

Figure 12 shows the effect of the atmospheric temperature $T_{\mathrm{s}}$ (see section 2.4) on the strain on the interface between the top and bond coats. The temperature fluctuation during spraying became larger when $T_{\mathrm{s}}$ was large. Then, the strain is considered to be larger because of the effect of the mismatch of the thermal expansion coefficient. The tendency of the final strain in Fig. 12 was affected by temperature gradient in the top coat when the surface was heated by spraying because the temperature gradient in the top coat became large when $T_{\mathrm{s}}$ was high.

Figure 13 shows the relationship among the average of temperature fluctuation during spraying $T_{\mathrm{f}}$, the total $\mathrm{AE}$ energy in each experiment and the simulated radial strain. Temperature history during spraying was expressed by $T_{\mathrm{f}}$. The diamond marks show the total AE energy of each experiment, and the square marks show the simulated radial strain on the interface between the top and bond coats when the deposition was finished. In this study, the temperature history during spraying was controlled by $T_{\mathrm{s}}$ in the simulation and the strain of each simulated condition was plotted at the position of $T_{\mathrm{f}}$ of the corresponded experiment of the center temperature of the specimen. Then, this figure showed a tendency that the AE energy in

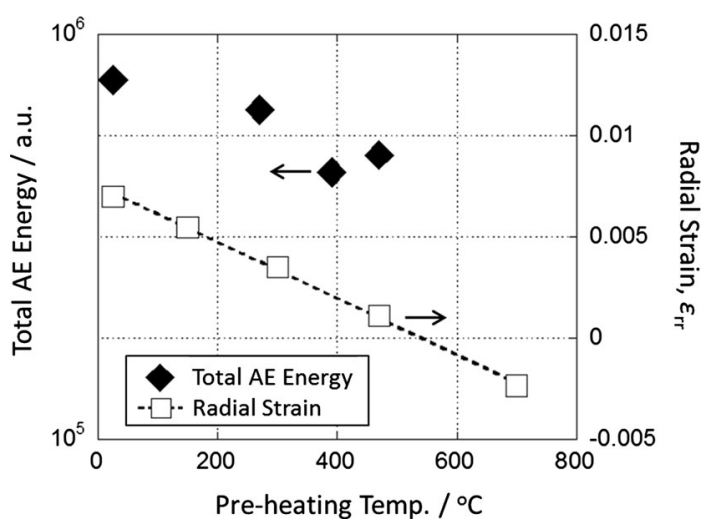

Fig. 11 The relationship between the pre-heating temperature of the specimen, the total AE energy in each experiment, and the strain in analyses with the loop pattern

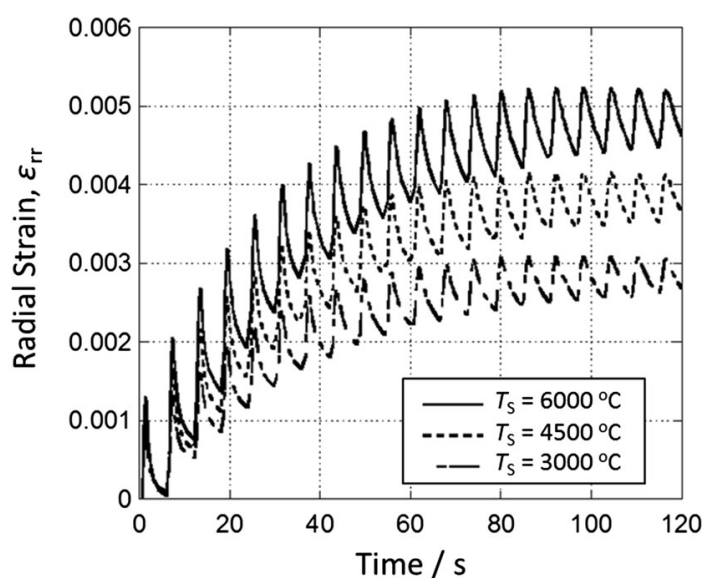

Fig. 12 Effect of the atmospheric temperature $\left(T_{\mathrm{S}}\right)$ on the strain $\left(\varepsilon_{\mathrm{rr}}\right)$ on the interface between the top and bond coats

the experiment and the strain in the simulation were increased when $T_{\mathrm{f}}$ was increased.

Furthermore, it was also revealed that the total AE energy in each experiment was corresponded to the crack development degree in the top coat. Especially, the almost all of the AE energy in Fig. 13 was due to vertical cracking and the radial strain was corresponded to this vertical cracks. Therefore, the simulated strain amount in this 


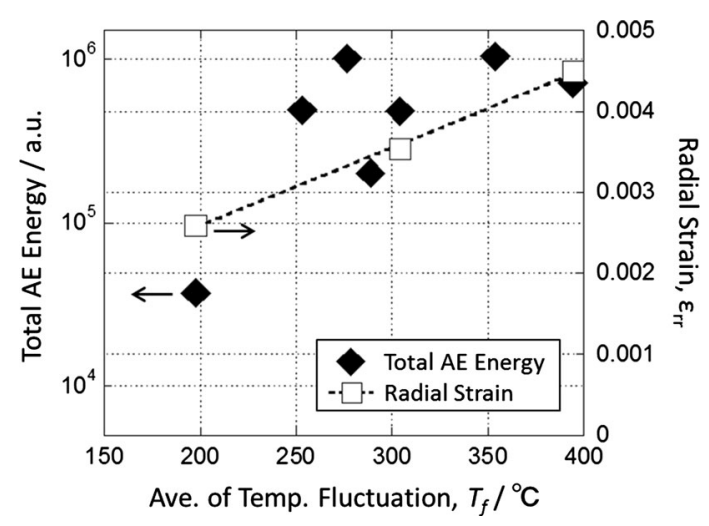

Fig. 13 Relationship among the temperature difference $\left(T_{\mathrm{f}}\right)$, the total AE energy in each experiment, and the strain $\left(\varepsilon_{\mathrm{rr}}\right)$ in analyses with the loop pattern

study can be corresponded to the crack development degree in the experiments.

\section{Conclusions}

A numerical study of stress and strain during thermal spraying was conducted, and the results were compared with that of the crack monitoring by non-contact laser $\mathrm{AE}$ measurement during plasma spraying process.

- Layer-by-layer model was used to simulate the deposition process of the top coat. Stress relaxation by crack generation was expressed by elasto-plastic behavior.

- Change of the radial strain with the depth in the top coat was also simulated. The radial strain became larger at the deeper area i.e., around the interface between the top and bond coats. Also, it corresponds to the observed results where the vertical cracks propagated from the deeper area to the surface in the top coat.

- The effect of initial temperature of the substrate was analyzed and higher initial temperature of the substrate showed smaller radial strain. This simulation result confirmed the experimental results of development of vertical cracks with variable pre-heating temperature of the substrate.

- The effect of atmospheric temperature was analyzed and lower atmospheric temperature showed smaller radial strain. This simulation result also confirmed the experimental results of the development of vertical cracks with variable plasma power.

- These FEA results explained the effect of temperature profile in the top coat on the crack generation during APS.

\section{Acknowledgment}

We are deeply grateful to Dr. Seiji Kuroda, Mr. Hiroshi Araki, Mr. Toshio Hiraoka, and Mr. Masayuki Komatsu for supporting experiments and analyses of APS. This work was partially supported by MEXT/JSPS KAKENHI Grant Number 23246124.

\section{References}

1. H.B. Guo, R. Vaßen, and D. Stöver, Thermophysical Properties and Thermal Cycling Behavior of Plasma Sprayed Thick Thermal Barrier Coatings, Surf. Coat. Technol., 2005, 192, p 48-56

2. S. Nishinoiri, M. Enoki, and K. Tomita, In Situ Monitoring of Microfracture During Plasma Spray Coating by Laser AE Technique, Sci. Technol. Adv. Mater., 2003, 4, p 623-631

3. K. Taniguchi, M. Enoki, M. Watanabe, S. Kuroda, and K. Ito, In-Situ Monitoring of Cracking Behaviors of Plasma Sprayed Coatings by the Laser Acoustic Emission Technique, J. Mater. Res., 2009, 24, p 3182-3189

4. K. Ito, S. Ohmata, K. Kobayashi, M. Watanabe, S. Kuroda, and M. Enoki, Crack Monitoring during Plasma Spraying of Ceramic Coatings by Non-Contact Acoustic Emission Method, Mater. Trans., 2010, 51, p 1272-1276

5. K. Ito, H. Kuriki, M. Watanabe, S. Kuroda, and M. Enoki, Detection of AE Events Due to Cracks in TBC During Spraying Process, Mater. Trans., 2012, 53, p 671-675

6. K. Ito, H. Kuriki, H. Araki, S. Kuroda, and M. Enoki, Detection of Segmentation Cracks in Top Coat of Thermal Barrier Coatings During Plasma Spraying by On-Contact Acoustic Emission Method, Sci. Technol. Adv. Mater., 2014, 15, p 035007

7. K. Ito, H. Kuriki, H. Araki, S. Kuroda, and M. Enoki, Generation Mechanism of Vertical Cracks in Top Coat of TBCs, J. Therm. Spray Technol., submitted

8. K. Sfar, J. Aktaa, and D. Munz, Numerical Investigation of Residual Stress Fields and Crack Behavior in TBC Systems, Mater. Sci. Eng. A, 2002, 333, p 351-360

9. M. Ranjbar-Far, J. Absi, G. Mariaux, and F. Dubois, Simulation of the Effect of Material Properties and Interface Roughness on the Stress Distribution in Thermal Barrier Coatings Using Finite Element Method, Mater. Des., 2010, 31, p 772-781

10. A. Gilbert, K. Kokini, and S. Sankarasubramanian, Thermal Fracture of Zirconia-Mullite Composite Thermal Barrier Coatings Under Thermal Shock: An Experimental Study, Surf. Coat. Technol., 2008, 202, p 2152-2162

11. A. Gilbert, K. Kokini, and S. Sankarasubramanian, Thermal Fracture of Zirconia-Mullite Composite Thermal Barrier Coatings Under Thermal Shock: A Numerical Study, Surf. Coat. Technol., 2008, 203, p 91-98

12. H.W. Ng and Z. Gan, A Finite Element Analysis Technique For Predicting As-Sprayed Residual Stresses Generated by the Plasma Spray Coating Process, Finite Elem. Anal. Des., 2005, 41, p 1235-1254

13. S. Widjaja, A.M. Limarga, and T.H. Yip, Modeling of Residual Stresses in A Plasma-Sprayed Zirconia/Alumina Functionally Graded-Thermal Barrier Coatings, Thin Solid Films, 2003, 434, p 216-227

14. Y. Chen, X. Liang, Y. Liu, J. Bai, and B. Xu, Finite Element Modeling of Coating Formation and Transient Heat Transfer in the Electric Arc Spray Process, Int. J. Heat Mass Transf., 2010, 53, p 2012-2021

15. S. Kuroda and T.W. Clyne, The Quenching Stress in Thermally Sprayed Coatings, Thin Solid Films, 1991, 200, p 49-66

16. P. Bengtsson and C. Persson, Modelled and Measured Residual Stresses in Plasma Sprayed Thermal Barrier Coatings, Surf. Coat. Technol., 1997, 92, p 78-86

17. T. Watanabe, I. Kuribayashi, T. Honda, and A. Kanazawa, Deformation and Solidification of a Droplet on a Cold Substrate, Chem. Eng. Sci. A, 1992, 47, p 3059-3065

18. Specification Sheet of Inconel ${ }^{\circledR}$ 601, Special Metals Corp

19. S. Rangaraj and K. Kokini, Estimating the Fracture Resistance of Functionally Graded Thermal Barrier Coatings from Thermal Shock Tests, Surf. Coat. Technol., 2003, 173, p 201-212 

20. V. Teixeira, M. Andritschky, W. Fischer, H.P. Buchkremer, and D. Stöver, Analysis of Residual Stresses in Thermal Barrier Coatings, J. Mater. Process. Technol., 1999, 92--93, p 209-216

đ:
21. H. Waki, H. Fujioka, and A. Kobayashi, Stress Histories of Yttria-Stabilized Zirconia and CoNiCrAlY Coatings During Thermal Spraying, J. Solid Mech. Mater. Eng., 2009, 3, p 199-209 